\title{
León Brunschwicg o El renacimiento del racio- nalismo en Francia
}

(Especial para ATENEA)

ASI todos los movimientos filosóficos de estos últimos veinte años han tendido a separar más y más la una de la otra: la filosofia y la ciencia. La psicologia que mezcla siempre la observación objetiva con la introspección, ha causado principalmente decepciones: ninguna teoria filosófica quisiera apoyarse en ella. Por lo demás, sociologia y psicologia en sus presuntuosos principios se habian divorciado de la filosofia para erigirse en ciencias exactas. El Bergsonismo fundado sobre la introspección y el Tomismo fundado sobre la revelación acentúan ese divorcio.

Desde algunos años León Brunschwicg. Miembro del Instituto. profesor en la Sorbona, ha dado a sus estudios una dirección totalmente distinta. Muy al corriente de las ciencias exactas y de su historia, autor de un libro sobre la evolución del pensamiento matemático. Brunschwincg es al mismo tiempo el mejor historiador de la filosofia del siglo XVII. Como Descartes y Spinoza, sus maestros en metafísica, estima que la filosofia debe ser una sintesis de las ciencias; en esos dominios, debe rendirnos servicios positivos, darnos consejos y direcciones prácticas. Su filosolia no es, pues, ni mística, como lo es en el fondo el bergsonismo, ni estética, como la doctrina si se quiere de Schopenhauer.

¿De qué naturaleza pueden ser los servicios a que nos referimos? No sólo de la de fijar los métodos, como la lógica aplicada. 
y dar el criferium de la verdad cientifica; sino aun de la de orientar los estudios científicos hacia tal o cual fin. Por ejemplo. le pertenece a la filosofía alentar o condenar la geometría Luclidiana, declarar que por falta de una aplicación suficiente de la quimica, la fisiologia sólo es aún una ciencia empírica y no una ciencia exacta, etc... etc...

Como sistema general que pueda ordenar el conjunto de esas nociones filosóficas. León Brunschwicg ha elegido la doctrina de Spinoza. No es sólo porque todos los descubrimientos posteriores de la ciencia han estado de acuerdo con las hipótesis de esta doctrina, sino aun por otras razones, que se parecen a razones cientificas. (o razones por las cuales se elige una hipótesis). Ese sistema es el más sencillo y el más económico: es decir. que resume el mayor número de hechos y leyes, en el orden más corto y con el menor número posible de suposiciones. Y también porque es el único enteramente libertado de las entidades o nociones vagas y abstractas que son a la filosofía lo que el horror del vacio. la virtud dormitiva de los cuerpos hipnóticos, y otras palabras huecas, fueron antaño a la fisica. Por ejemplo. Spinoza es el único que prescinde de las facultades del alma y que explica las leyes del espiritu sin nociones negativas. De todo esto resulta que, continuando el espíritu spinozista. León Brunschwincg establece más bien un parentezco entre la filosofia y las ciencias exactas. Gran diferencia con la filosofia francesa del siglo XIX. que se apoyó más bien sobre las ciencias naturales que permanecian aún empíricas e inciertas. León Brunschwicg no es partidario de que se busque en las nociones confusas de la medicina moderna. y su descripción incompleta de los nervios y del cerebro, una explicación del espíritu humano. Prefiere buscar las leyes de ese espiritu humano en sus obras más perfectas. es decir. las ciencias. En la gran obra que Brunschwicg prepara actualmente sobre los progresos del pensamiento occidental, muestra cómo el espiritu está siempre presente en los descubrimientos cientificos, cómo está presente en las leyes que constata, y cómo la conciencia 
que él toma de sus leyes, junto con las leyes del mundo, se hace más y. más pura y nitida.

La Torma de los trabajos de León Brunschwicg es demasiado abstracta y dificil para el gran público. (Hasta temo que la forma de esos estudios sea demasiado árida). Sin embargo, el pensamiento de León Brunschwicg está en profunda armonia con el pensamiento de nuestro gran poeta Paul Valéry, por ejemplo. Es también en los grandes sabios y en los individuos superiores en quienes Paul Valéry cree que se deberia estudiar el espiritu humano. Por lo demás, el pensamiento filosófico de Valéry se parece también al de un Spinoza intuitivo.

Es en el veraneo y Sociedad de Conferencias de Pontigny donde León Brunschwicg ha leido por primera vez su libro sobre los progresos del pensamiento occidental.

De pensamiento tan elevado como sus libros anteriores. éste se mostrará más accequible al público y revelará por vez primera en toda su actitud una de las inteligencias más vastas y abiertas que se pueda conocer. A pesar de sus cabellos blancos y su carrera ya larga. León Brunschwincg conserva todas las curiosidades y todo el ardor intelectual de la juventud.

Un año atrás, me habia tocado dar cuenta en la Nouvelle Revue Française, del libro que Brunschwicg ha consagrado al genio de Pascal (y aquel libro es el más sintético. el más preciso y perfecto sobre el espíritu cientifico de Pascal que hasta hoy se haya escrito). Recibi del profesor una carta encantadora. que me probaba que habia leido hasta mi primer cuentecillo filosófico: y yo contaba quizás entonces con mil lectores, pues no habia dado aún ninguna obra de tiraje ilimitado. Sin duda se unia a su aprobación una razón de doctrina: me juzgaba convencido spinozisla. Le gusta aconsejar a los jóvenes: pero lo que les aconseja es la libertad y la originalidad, hasta si aminora en ellos el respeto hacia sus mayores. Un dia en que yo formulaba mi asombro de verlo reunir en su cerebro el conjunto de la filosolia y el conjunto de las ciencias exactas. él me contestó sonriendo: „Por ventura soy rico. y he podido eliminar a los parásitos». Y por lo que agregó he podido ver 
lo que él llama sparásitos»: no sólo las preocupaciones materiales, sino todos los placeres, y hasta casi el descanso. Los miles de horas de trabajo que representa cada uno de sus libros no pesan en su alegria ni aminoran el ardor con que se dedica al futuro libro.

La resurrección, últimamente, del kantiano y spinozista Lagneau, el éxito creciente de la estética y de la moral de Alain. extraida de Descartes y Spinoza, y por lo tanto cercanas parientes de la filosofia de Brunschwicg. parece que deben atraer hacia él la mayor parte de la filosofia francesa. Las recientes irrupciones de la filosofia en las ciencias. (problema de la relatividad, constitución de la materia, etc.) parece que deben trasportar la metafísica fuera de la intuición y de la revelación, hacia el campo de los problemas arduos y positivos a los cuales León Brunschwicg ha consagrado su vida. 